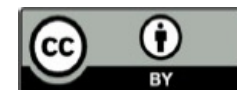

\title{
Features of the Transition From the Traditional to the Criterial Assessment in Schools of Kazakhstan
}

\author{
Kenzhetaeva Roza" ${ }^{1 *}$ Nurzhanova Sazhila1, Beimisheva Aigul², Stambekova Assel', Ryabova Ekaterina1, Kulbayeva Dina³
}

${ }^{1}$ Institute of Pedagogy and Psychology, Department of Pedagogy and Methods of primary education, KazNPU named after Abai, Dostyk ave., Almaty, Kazakhstan, e-mail: Kengetaewa@mail.ru; sajila@mail.ru; stambekova_81@mail.ru; ekrina22@gmail.com 2University "Narxoz", Almaty, Kazakhstan, e-mail: Aigulb777@gmail.com

${ }^{3}$ Faculty of law, Department of Philosophy and political science, Taraz State University named after M.Kh.Dulati, Taraz, Kazakhstan, e-mail: kulbaeva68@bk.ru

\begin{abstract}
This study discusses the features of the transition from the traditional assessment system to the criteriabased assessment in schools of Kazakhstan. The use of criterion assessment in schools in Kazakhstan contributes to the crowding out of traditional methods of assessment and leads to a new vision of the methods and technologies of the system for evaluating educational achievements. In connection with the modernization of Kazakhstan's education, significant changes are occurring in the control and assessment activities of Kazakhstan schools, its goals, content, and technologies are changing. The problem of assessment activity is one of the most urgent problems both in pedagogical theory and in pedagogical practice. This study presents the results of empirical studies and the features of the transition to a new criteria-based assessment system for Kazakhstan. According to the results of the study, the problem of the need for professional training of future primary school teachers for the criteria-based assessment system was revealed. Results also showed that there are difficulties of applying criteriabased assessment in the practice of primary school teachers. The question of what professional knowledge, skills, and abilities an elementary school teacher must possess to successfully perform the monitoring and evaluation function was investigated. Particular attention is paid to the study of the influence of criteria-based assessment on learning motivation in primary school. Keywords: criteria-based assessment, control and assessment activities, vocational training, pedagogical education.
\end{abstract}

\section{Introduction}

Kazakhstan at the turn of the XX-XXI centuries after the collapse of the Soviet Union has undergone changes in various areas, including the education system. One of the important conceptual provisions for updating the content of education in the $21^{\text {st }}$ century is the transition to 12-year education and a change in the system for evaluating student academic achievements. In the last twenty years, special attention of Kazakhstan and the pedagogical community has been drawn to the issues of the quality of education and the improvement of its assessment. The importance of changing the system of assessing the educational achievements of students in Kazakhstan is determined by the modern strategic objectives of education, the need to improve the level of education in accordance with international standards. The assessment system should provide an opportunity to determine how well the student has mastered the educational material or has developed a practical skill; show the dynamics of student success in various areas of cognitive activity; be based on a mechanism that encourages, develops and promotes students' selfesteem.

Schools of Kazakhstan since the 2016 academic year have gradually moved to a new system for assessing academic achievement, based on the criteria-based assessment system. In this regard, the essence of this article is to study the professional training of future primary school teachers for assessment activities, namely, criteria-based assessment. International comparative studies (PIRLS, TIMSS, PISA, etc.) had a significant impact on the theory and practice of monitoring and assessment in schools in Kazakhstan. They provided an opportunity to get acquainted with international standards for assessing the quality of education and offered tools to assess the achievements of students in certain educational areas. This criteria-based assessment tool becomes a new approach to learning. 
The following general terms and their definitions are included in the section "General Provisions" of the State Compulsory Standard of Primary Education:

1) assessment criteria - statements that allow teachers and students to recognize whether the goal of learning has been achieved, and serve as the basis for making decisions on the assessment of students' achievements,

2) formative assessment - a type of assessment, which is carried out in the course of daily work in the classroom, is a current indicator of student performance, provides an operational relationship between the student and the teacher during the training, feedback between the student and the teacher and allows you to improve the educational process,

3) summative assessment - a type of assessment that is carried out at the end of a certain academic period (quarter, trimester, academic year), as well as the study of sections in accordance with the curriculum (State obligatory standard of primary education of the Republic of Kazakhstan, 2016).

From this, it can be concluded that the introduction of criteria-based assessment comes from the main regulatory document - the State Compulsory Standard of Primary Education of the Republic of Kazakhstan. In this regard, the question raises the necessity for professional training in the field of criteriabased assessment of students' academic achievements as seen in Tukaiev, et al. (2019).

Criteria-based assessment is defined as a process based on a comparison of students' learning achievements with clearly defined criteria, collectively developed criteria that are known in advance to all participants of the process, consistent with the goals and content of education, contributing to the formation of students' learning and cognitive competence (The system of criteria-based assessment of educational achievements of students (Tenekeci and Uzunboylu, 2020)).

Theoretical studies and the experience of a number of countries in applying criteria-based assessment showed that it turned out to be one of the most effective ways to improve the educational achievements of each student, as well as to reduce the distance between the most successful students and students who have serious learning difficulties. Assessment for learning is the process of finding and interpreting evidence that allows students and their teachers to understand at what stage of learning they are and in which direction they should go. Analysis of psychological and pedagogical literature gives grounds to assert that at all stages of the development of the education system; monitoring and evaluation of students' achievements occupied an important place in pedagogical research and reflected the specifics of these stages.

The assessment process is subjected to development and is a dynamic process. The theoretical premises are the work of such researchers including Karimsakova, et al. (2018). The authors have proved the need to create a universal system of assessment that meets all the requirements of modern society and the needs of the individual student. A significant contribution to the development of the assessment theory was made by domestic researchers, who defined the assessment as the result of learning activities, they noted the systematic nature of the assessment process, and suggested that the assessment should be carried out with a predetermined standard. No less significant, in the opinion of scientists, are such problems as the competent organization of the assessment process with the aim of forming students' learning and cognitive motivation and stimulating learning achievements. For the present study, the works of Zolotova, Mayorov, Ibatova, Chernilevsky, who propose to consider the criteria-based assessment as a benchmark, an indicator of the level of proficiency of educational material, which has a value of incentive to improve the educational achievements of students.

The problem of the transition from the traditional assessment system to the criterial one was studied by Krasnoborova (2010), who addressed the problems of teachers' assessment activities and proposed criteria - based assessment technologies. According to Krasnoborova (2010), the problem of assessing the educational achievements of students can be solved by forming a criteria-based assessment of the results of students' mastering basic educational programs already at the initial stage of education.

The dissertation research of scientists such as Selishcheva (2014) on the influence of the criterion system of assessing the educational achievements of students on their personal characteristics, Kuznetsova (2017) on the system of monitoring and evaluation of educational achievements of younger students as a factor in improving the quality of education.

Karimsakova et al. (2018) describes assessment as the process of matching the result, and most importantly, the course of activity with the ideal sample outlined in the task. Karimsakova et al. (2018) distinguishes between the essence of the concepts of "assessment" and "mark". "Assessment is a process, activity (or action) of evaluation carried out by a person; the mark is the result of this process, this activity (or action), their semi-formal reflection.

Zuckerman (2015) points to the need to replace the mark with a comprehensive system of evaluative relationships, cooperation of students and teachers in the production and application of assessment. This 
cooperation is aimed at developing schoolchildren's abilities and skills of self-assessment as the most important component of self-learning. Under the assessment of the quality of knowledge and skills of school children and implies the existence of a definite link between the plan and the reflected information.

The concept of formative assessment, as a new pedagogical tool, fully consistent with modern educational values and objectives. It is based on targeted support of training that actualizes the learning independence of each student, helps him independently find the best strategies and ways of his learning activities. Problems of pedagogical process organization and its perfection, also primary school teachers' competency were considered in the research works of scientists who presented research results from Kazakhstan (Uzunboylu et al, 2017; Sartayeva, 2018).

The study of the features of the application of criteria-based assessment revealed a number of existing contradictions between:

- the need of the society and the individual student in the new objective system of assessment of educational achievements on the one hand, and insufficient development of the criteria-based assessment system, on the other,

- the current scientific and theoretical basis on the issue of assessment and lack of professional preparedness for criteria-based assessment,

- the use of the practice of criteria-based assessment in schools and the theoretical insufficiency of teaching and learning materials, special courses on the criteria-based assessment of the educational achievements of students.

Based on the above contradictions, the aim was to identify the features of the transition from the traditional to the criteria-based assessment in schools of Kazakhstan, to prepare scientifically-based proposals for the professional training of teaching staff to the criteria-based assessment system.

The criteria-based assessment system, which makes it possible to deviate from the subject-expert assessment of knowledge in the long term, is aimed at developing a competitively capable personality, ready to interact with the outside world, self-learning and personal self-determination. In this case, the student's activity, his involvement in the educational process is ensured by the fact that the criteriabased assessment performs the function of feedback when the student receives information about his successes and failures. Thus, solving the problem of objective assessment of students, the criteria approach encourages them to achieve not only a higher result, but also to set goals in the educational process on their own.

Furthermore, despite the significant number of theories concerning the problem of pedagogical assessment, scientists continue to look for ways to modernize the regulatory assessment system used in most schools, pointing to its imperfection. Obvious is the fact that the monitoring and evaluation of the educational achievements of students is one of the most important and necessary components of the learning process and involves the systematic observation of the teacher as the teaching progresses at all stages of the learning process. The problem of assessment activity remains one of the most urgent problems both in pedagogical theory and in pedagogical practice.

The aim of the study is to identify the level of professional preparedness of pedagogical university students in the specialty: "Pedagogy and methodology of primary education" for the criteria-based assessment of educational achievements. Research objectives: to determine the level of preparedness of pedagogical universities students for criterion assessment; identify the difficulties and shortcomings of preparedness for the application of criterion assessment.

\section{Materials and Methods}

In order to achieve the aim of the study, these methods are used; analysis of philosophical, social, psychological, pedagogical and methodical literature from the point of view of the research problem, synthesis, generalization of pedagogical publications and regulatory documents, advanced pedagogical experience, conducting a sociological survey, comparative analysis, evaluation and synthesis of results. According to a unified methodology, a survey of 100 respondents aged 21 to 35 years was conducted. The survey was conducted by an initiative group, which included the entire team of authors.

The research methodology is based on the application of international standards when choosing a research methodology and conducting a survey. Respondent selection method - quota sample of $50 \%$ of students in the pedagogical specialty "Pedagogy and methodology of primary education" and primary school teachers in Almaty, $50 \%$ of young specialists. Only 100 respondents. This sample is representative, as the subject under study is specific. Consequently, only those respondents who really relate to the teaching process took part in the study. 
The study examined the following aspects of the subject:

- Difficulties in applying criteria-based assessment (application in the lower grades, difficulties in evaluating, ways to solve problems),

- Preparing primary school teachers for criteria-based assessment (deficiencies in training, professional knowledge, and skills of the teacher),

- Special preparation for criteria-based assessment (within the framework of the university program, special courses, advanced training).

\section{Data collection}

The main method of collecting primary information is a questionnaire. The choice of a quantitative method of collecting information is due to the need to maximize the coverage of teachers as the main agents for introducing criteria-based assessment into practice, that is, into the education system. In the course of the experiment, a sociological survey in the form of a survey was conducted, where respondents answered the following questions:

1. What more influences the level of training in the field of criteria-based assessment?

2. What are the difficulties in applying criteria-based assessment?

3. How do you solve the difficulties of applying criteria-based assessment?

4. What are the disadvantages in preparing primary school teachers for criteria-based assessment?

5 . What should be professional knowledge and skills of a primary school teacher?

6. What should be professional qualification in the field of criteria-based assessment?

7. Do you consider it sufficient to prepare for criteria-based assessment within the framework of the university curriculum?

8. What special courses are necessary for the professional preparation of students for criteriabased assessment?

9. What are your suggestions for improving the training of future primary school teachers for criterion assessment?

\section{Data analysis}

All obtained survey results were processed in the statistical information processing program SPSS. Version 21.

\section{Results}

The subjects of the study are students, undergraduates, doctoral students of KazNPU named after Abai, and primary school teachers from different schools of the Almaty city. Primary school teachers were represented in the amount of $38 \%$. The experts included members of the working group on the development of criteria for criteria-based assessment, as well as teachers of the largest pedagogical universities of the Republic of Kazakhstan (11\%).

\section{Graphical representation of participants of this research}

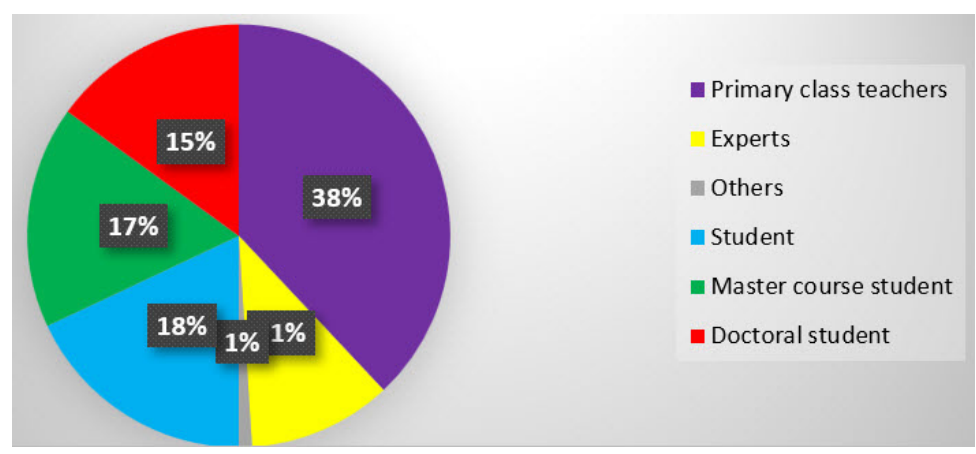

Figure 1. Representation of participants

In Figure 1 seen that, students (18\%), undergraduates (17\%), doctoral students (15\%) took part in the study of trainees. Primary school teachers were represented in the amount of $38 \%$. The experts included teachers from the largest pedagogical universities of the Republic of Kazakhstan (11\%) and 
others (1\%). A survey among teachers showed that $91 \%$ of teachers work according to an updated curriculum, namely, the criteria-based assessment system. Only $9 \%$ continue to work on the traditional.

According to the results of the survey, the opinions of respondents on each question of the survey were analyzed and presented below. What really affects the quality of the level of training for the implementation of criteria-based assessment? Opinions of experts on this issue are divided. The group of future specialists, which included students, undergraduates, and doctoral students, was asked about what has a greater impact on training in the field of criteria-based assessment.

\section{Factors that influence criterion assessment training}

In Figure 2, results of the study showed that $62 \%$ of future teachers believe that the most important are the knowledge and skills acquired in specialized courses on criteria-based assessment. It should be noted that such courses include master classes, trainings and much more. Every fifth respondent noted that the most important are the knowledge and skills acquired in the framework of the university curriculum (22\%). $14 \%$ of future teachers who were surveyed believe that the necessary knowledge and skills are acquired only in the course of work, namely practical work. Only $2 \%$ of respondents are confident that self-education can influence the level of training in the field of criteria-based assessment.

\section{What more influences the level of training in the field of criterion assessment?}
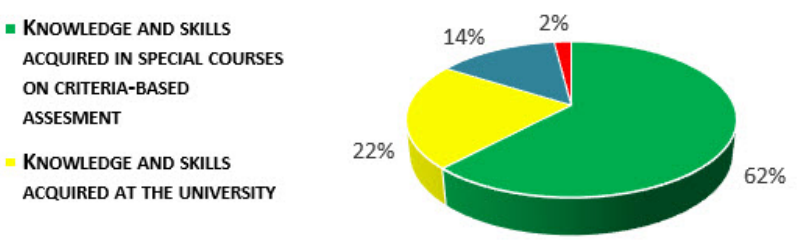

Figure 2. Impact on education in the field of criteria-based assessment

This research finding is supported by other studies (Kazmagambetov and Kenesbaev, 2003; Petrov, 2001; Amirova et al., 2018).

As part of a sociological study, teachers and experts were asked to analyze and name the main difficulties in applying criteria-based assessment.

\section{Difficulties in applying criteria-based assessment}

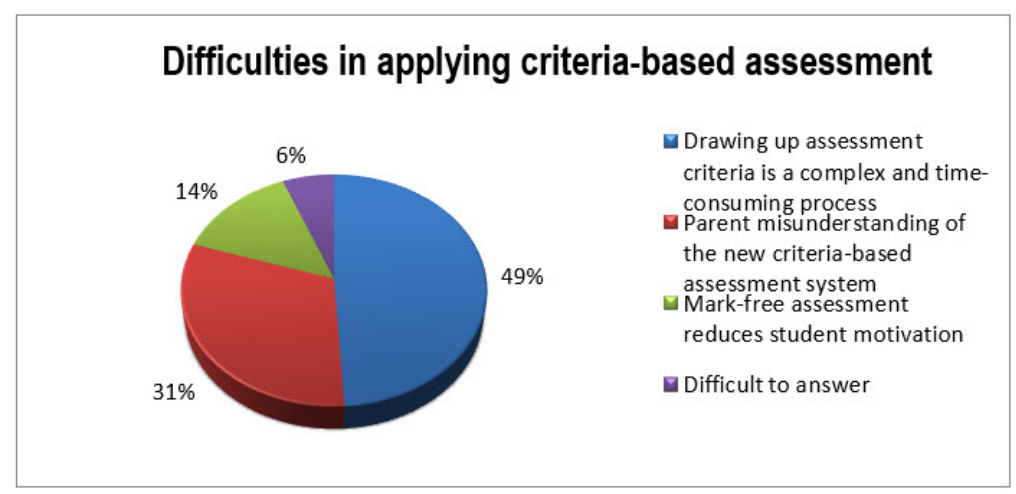

Figure 3. Impact on education in the field of criteria-based assessment

In Figure 3 seen that, it was found that almost half of the respondents considered the most difficult to compose qualitative assessment criteria, which is a complex and time-consuming process - $49 \%$. In addition, another serious problem is the misunderstanding of the parents of the new criteria-based assessment system, and, as a result, the lack of support from them. So, says $31 \%$ of experts. Separately, the motivation of pupils should be noted. According to the traditional learning system, pupils, receiving daily grades, were motivated in daily preparation for classes. Under the new criteria-based grading system, there is no daily marking; the marks are put at the end of the section on this subject and at the end of the study quarter. $14 \%$ of experts call this a serious problem and the difficulty of applying criteriabased assessment. $6 \%$ of respondents found it difficult to answer this question. 


\section{How do you solve the application difficulties in criteria-based assessment?}

When the responses to "How do you solve the difficulties of applying criteria-based assessment?" are considered, to solve all the problems mentioned above and the difficulties of applying criteria-based assessment, experts suggest these solutions. $58 \%$ of teachers and experts prefer to attend seminars, workshops, training on the control and assessment of educational achievements. $22 \%$ are mainly engaged in educational work with parents, explaining the nature and essence of the new assessment system. 18\% of respondents prefer to educate themselves.

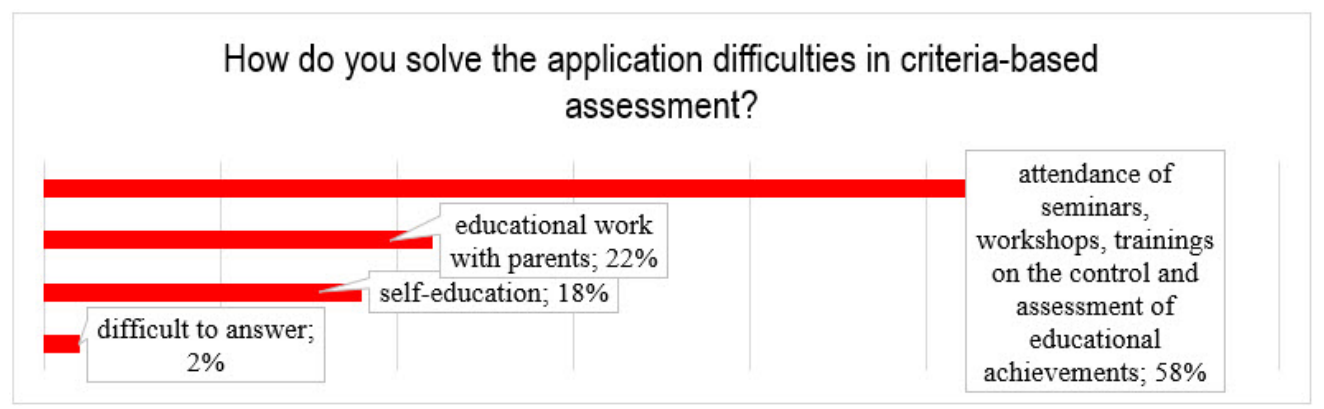

Figure 4. How do you solve the difficulties of applying criteria-based assessment?

In Figure 4 seen that, it can be concluded that the majority of respondents $(58 \%)$ have a need to attend seminars, master classes, and training sessions on the use of criteria-based assessment.

\section{Shortcomings of experts in the field of education}

In Figure 5 seen that, the significance of the survey results is also confirmed by the result of the following question, within the framework of which it was established that a significant drawback in teacher training is the insufficient number of special courses according to the $-40 \%$ assessment criterion. Therefore, it is necessary to strengthen the training of specialists with the help of a qualitative increase and strengthening of special courses on criteria-based assessment.

In addition, $28 \%$ of respondents noted that the number of educational and methodical literature on the given problem is not enough. Such a problem really exists since criteria - based assessment was introduced relatively recently and existing materials are still fragmented. Sixteen percent (16\%) of experts believe that special seminars, workshops, and trainings for teachers are not enough. Twelve percent $(12 \%)$ of respondents believe that the university system of training is imperfect and requires significant changes.

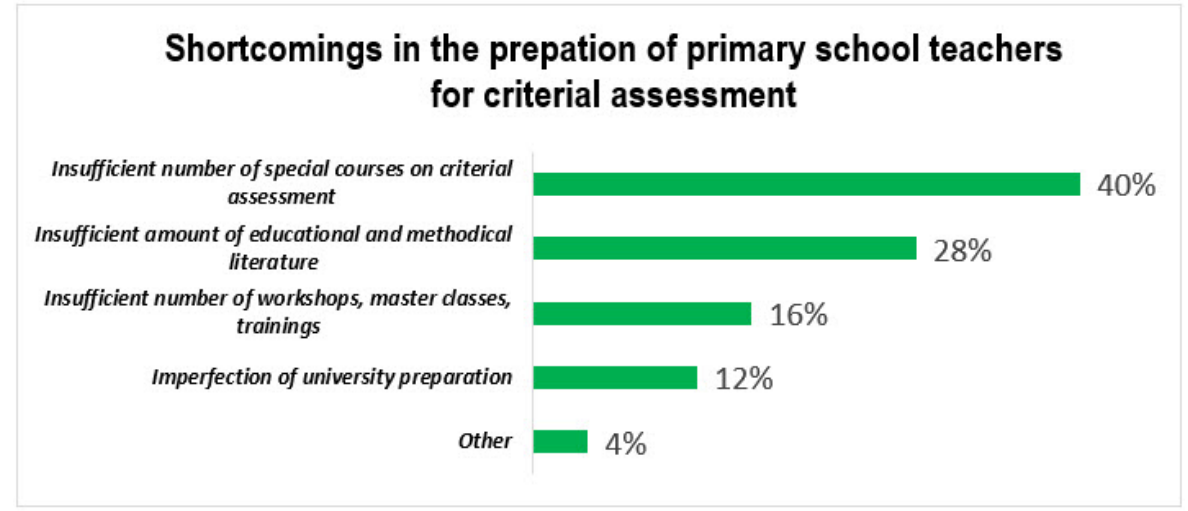

Figure 5. Experts working in the field of education

As can be seen from the data obtained, experts working in the field of education indicate mainly the lack of high-quality training of specialists and the lack of educational literature Figure 5).

According to the survey results, the majority of trainees (46\%) believe that the most important thing in the work of a primary school teacher is "Knowledge and understanding of the essence and technology of criteria-based assessment". The opinion of most experts on this issue is slightly different from the views of trainees. $40 \%$ of the experts surveyed believe that the most important professional knowledge and skill is the person himself, the teacher, namely his "Interest and motivation towards the teacher's profession". 
In addition, according to both groups, creative and imaginative approach to the work of the teacher is especially important in the work of the teacher (14\% of students and $10 \%$ of experts). Consequently, the work on the updated program requires maximum creativity.

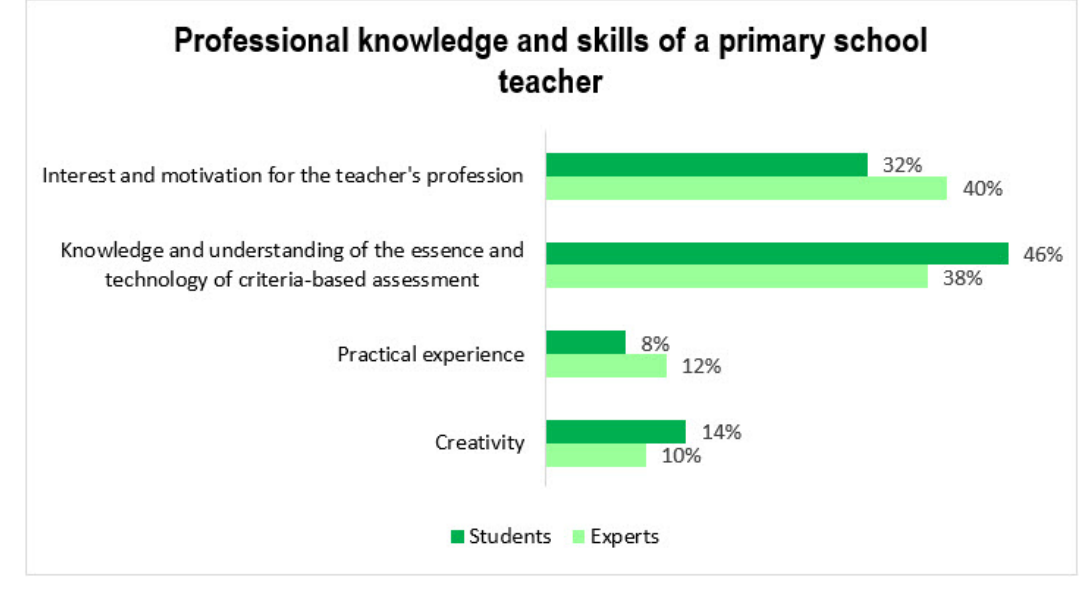

Figure 6. Teaching in the updated system

An interesting fact is that the "Practical experience" option scored the least number of votes in our survey, $12 \%$ of experts noted the importance of practical experience and $8 \%$ of students.

\section{Discussion}

Most teachers believed that the skills and knowledge of the teacher was what mattered most when it comes to specialized courses focused on the application of criteria-based assessment. They therefore suggested the inclusion of these skills and knowledge in their curricula in the universities. Master classes, trainings, practical and course work are some of the mediums to achieve knowledge of this criteriabased assessment in teachers. This research finding is supported by other studies (Kazmagambetov and Kenesbaev, 2003; Petrov, 2001; Amirova et al., 2018).

It is therefore not surprising that despite all the difficulties of implementing criteria-based assessment, schoolteachers prefer to improve their own qualifications using methods available, such as attending seminars, master classes, and various trainings. Irrespective of the fact that criteria-based assessment was introduced relatively recently into Kazakhstan's education system, today it is necessary to think about a qualitative change and improvement in the training of future specialists, especially primary school teachers, since it is in an elementary school that the foundations and interest in the entire future school are laid (Selischeva, 2014). Thus, it becomes obvious that if for a group of students the process is the main thing, namely the introduction of criteria-based assessment, then for a group of professors and teachers the main thing is the teacher himself, his interests and motivation. Also, experts made suggestions and wishes about what they would like to see or change in the criteria-based assessment system. The following proposals were received to improve the preparation of future elementary school teachers for the criteria-based assessment of student's performance: a greater number of teaching and learning aids are needed; it is important to provide feedback to parents, develop clear criteria and assessment tools, and conduct practice-oriented special courses on criteria-based assessment for students of pedagogical universities and teachers.

Another point for consideration, however, is the fact that lack of literature and high-quality training materials affect the criteria-based assessment method of teaching. The absence of this necessary materials could affect how teachers transmit information to their students, irrespective of their level of knowledge or skills. This finding is supported by other research findings (Lin, Lin and Laffey, 2008; Ishnaiwer, 2020).

The results of this survey allow us to conclude that the main problem of the implementation of criteria-based assessment is the process of creating qualitative criteria, since this process requires a lot of time and energy. In addition, it is clear that the introduction of criteria-based assessment should not take place unilaterally, that is, there should be a discussion with the parents of the students, and explanatory work should be done on the advantages of the new educational system. What together causes misunderstanding on the part of parents and, often, discontent. It is necessary to explain in detail and explain directly to schoolteachers. 


\section{Conclusion}

In accordance with the purpose and objectives of our study, the values of such concepts as "criteriabased assessment", "assessment criteria", "formative assessment", and "summative assessment" are defined. Based on the purpose of the study, the features of the transition from the traditional to the criteriabased assessment in schools in Kazakhstan were identified and prepared scientifically-based proposals for the professional training of teaching staff for the criteria-based assessment system.

Therefore, having studied and analyzed the works of scientists, as well as the results of our empirical research, these conclusions can be drawn: the application of the criteria-based assessment system in the schools of Kazakhstan complies with the state compulsory standard of primary education and in the long term is aimed at developing a competitive personality. Monitoring and assessing student achievement is one of the most important and necessary components of the learning process. According to the results of the study, the majority of respondents have a need to attend seminars, master classes, and trainings on the use of criteria-based assessment. In an empirical study, it was found that the main shortcoming in the preparation of primary school teachers for criteria-based assessment is the insufficient number of special courses on criteria-based assessment. There is a need for professional training of pedagogical personnel in the field of criteria-based assessment of students' educational achievements.

Therefore, summarizing the results of our research, it was revealed that the use of the criteria-based assessment system in schools in Kazakhstan is relevant and effective. The new system for evaluating students' educational achievements requires the training of teachers, the development of educational and methodological literature, and conducting explanatory work with the parents of students. Particular attention should be paid to the professional training of students at pedagogical universities and the conduct of special courses for them on criteria-based assessment. In the future, on the basis of the study, it was planned to propose a model, its structure and content for the preparation of future teachers for the criteria-based assessment of the educational achievements of primary school students.

On the basis of the conducted research, conclusions are drawn on the need to increase the level of professional training of students at pedagogical universities in the field of criteria-based assessment. In connection with the above, it should be aimed to study and facilitate the professional training of students at pedagogical universities and elementary school teachers for criteria-based assessment.

\section{Acknowledgments}

We would like to thank our university rectors and everyone who contributed to this research.

\section{Conflict of interests}

The authors declare no conflict of interest

\section{References}

Amirova, A., Buzaubakova, K., Kashkynbayeva, Z., Yelubayeva, M., Kumisbekova, Z., Elmira, U., \& Genc, Z. (2018). Training the creative competence of future teachers. Journal for Educators, Teachers and Trainers, 9(2), 118-125. Retrieved from https://jett.labosfor.com/article_888_ae8b134d465f337e9af10c3b634c13b4.pdf

Ishnaiwer, M. (2020). Incorporating systemic functional linguistics in the unlock course book: English intermediate level at Birzeit University. Global Journal of Foreign Language Teaching, 10(1), 49-57. https://doi.org/10.18844/giflt.v10i1.4478

Ibatova, A. Z. (2020). Development of a criteria apparatus for assessing the students' readiness for a dialogue in general and business sphere. Universidad y Sociedad, 12(2), 48-52. Retrieved from https://rus.ucf.edu.cu/index.php/rus/article/ view/1479/1495

Karimsakova, B., Abenova, N., Sahipova, G., Zhumabaeva, T., Kulkaeva, Z., \& Imanbaeva, A. (2018). Experience of Application and Assessment of Effectiveness of Active Training Methods. An Acad Bras Cienc, 90(3). Retrieved from https://sirius. zkgmu.kz/sirius/src/PpsModuleFiles/publication/25/372_319_375_aabc-2017-1045indd.pdf

Kazmagambetov, A. G., \& Kenesbaev, S. M. (2003). Informatization of education and its impact on teacher training. Lecture notes of the international conference "The development of information technology in higher education." - Almaty.

Krasnoborova, A. A. (2010). Criteria-based assessment as a technology for the formation of educational and cognitive competence of students (Unpublished Phd thesis). Nizhny Novgorod, Russia.

Kuznetsova, M. I. (2017). The system of monitoring and assessment of educational achievements of younger students as a factor in improving the quality of education. Retrieved from https://cyberleninka.ru/article/n/what-factors-help-andhinder-children-s-progress-in-reading on 21 February 2019.

Lin, Y. M., Lin, G. Y., \& Laffey, J. M. (2008). Building a social and motivational framework for understanding satisfaction in online learning. Journal of Educational Computing Research, 38(1), 1-27. https://doi.org/10.2190/EC.38.1.a

Petrov, A. V. (2001). Methodological and methodological foundations of personality-developing computer education. Russia: 
Monograph, Volgograd.

Razinkina, E. M. (2003). Information technology as a means of developing the professional potential of a future specialist. Computer Science and Education, 3, 117-119.

Tashkenbayevna, N., Kenesbaev, S. M., Zhailauova, M. K., Elmira, U., Nurzhanova, S. A., \& Stambekova, A. S. (2018). Possibilities of the Subject 'Information and Communication Technologies' in Accustoming Primary School Students to Research Activities. International Journal of Interactive Mobile Technologies (iJIM), 12(6), 35-46. https://doi. org/10.3991/ijim.v12i6.9622

Selischeva, E. A. (2014). Influence of the criteria-based assessment system of educational achievements of students for 7-8 grades on their personal characteristics (Unpublished Phd thesis). Moscow.

Sartayeva, R. (2018, May). New „Being "of Human and Category of „Information "in the Space of Modern Civilization. In Proceedings of the XXIII World Congress of Philosophy (Vol. 46, pp. 81-88). https://doi.org/10.5840/wcp23201846931

Tenekeci, F., \& Uzunboylu, H. (2020). Determining the relationship between the attitudes of private teaching institution teachers towards lifelong learning and their competence. International Journal of Learning and Teaching, 12(1), 1-16. https://doi. org/10.18844/ij|t.v12i1.4559

Tukaiev, S., Dolgova, O., Lysenko, O., Fedorchuk, S., Havrylets, Y., Rizun, V., ... \& Van den Tol, A. M. (2019). Amateur sport and emotional burnout formation in high school students. Contemporary Educational Researches Journal, 9(4), 103109. https://doi.org/10.18844/cerj.v9i4.4328

Uzunboylu, H., Turalbayeva, A. T., Sultanbek, M., Utyupova, C. E., Aidarov, B. Z., Uaidullakyzy, \& E., Zhumash, Z., (2017). The general preparation of the training of elementary school and the family and the education of gifted children school in cooperation principles. Ponte, 73(4), 239-251. https://doi.org/10.21506/j.ponte.2017.4.54

Zuckerman, P. (2015). Faith no more: Why people reject religion. Oxford University Press. https://books.google.com.cy/ books?hl=tr\&|r=\&id=UuURDAAAQBAJ\&oi=fnd\&pg=PP1\&dq=Zuckerman+(2015)\&ots=pY0Sm7buh-\&sig=ovfy zB0q0BMPV3QqGfXLgYYnZY\&redir_esc=y\#v=onepage\&q=Zuckerman\%20(2015)\&f=false 
Kenzhetaeva R. et al. (2020). Features of the transition from the traditional to the criterial assessment in schools of Kazakhstan, International Journal of Cognitive Research in Science, Engineering and Education (IJCRSEE), 8(3), 73-81. 